\title{
Effect of boundary conditions on the hydraulic behavior of geotextile filtration system
}

\author{
Hsin-Yu Shan ${ }^{\mathrm{a}, *}$, Wu-Liang Wang ${ }^{\mathrm{a}}$, Ting-Chang Chou ${ }^{\mathrm{b}}$ \\ ${ }^{a}$ Department of Civil Engineering, National Chiao Tung University, 1001 Ta Hsueh Road, Hsinchu, Taiwan \\ ${ }^{\mathrm{b}}$ Construction Bureau of Kao-Hsiung County, Taiwan
}

Received 1 February 2001; received in revised form 13 July 2001; accepted 20 July 2001

\begin{abstract}
There are several test methods available for studying the behavior of geotextile/soil filtration systems. However, there has not been a consensus on which one of these methods should be the most appropriate. In this research, gradient ratio (GR) tests and hydraulic conductivity (HCR) tests were performed to evaluate the effects of boundary conditions on the behavior of geotextile/soil filtration systems. The test results show that the hydraulic conductivity of the filtration systems decreased as the effective stress and hydraulic gradient increased. Furthermore, the hydraulic conductivity obtained from GR tests with a hydraulic gradient of 5 could be taken as the lower bounds for HCR test results. Therefore, it is suggested that the GR test can be used to obtain reasonable and conservative design parameters of the filtration systems. (C) 2001 Elsevier Science Ltd. All rights reserved.
\end{abstract}

Keywords: Geotextile; Filter; Hydraulic conductivity ratio; Gradient ratio

\section{Introduction}

There are several test methods available for determining the hydraulic conductivity and assessing the clogging potential of a geotextile/soil filtration system. Among these tests, the gradient ratio (GR) test is most widely used. However, the hydraulic conductivity ratio (HCR) test seems to be able to closely simulate the actual at service condition.

Hydraulic conductivity of soils depends on the boundary conditions applied by the testing system. Two of the most important features that control the results of

*Corresponding author. Tel.: + 886-3-571-2121; fax: + 886-3-571-6257.

E-mail address: hyshan@cc.nctu.edu.tw (H.-Y. Shan). 
permeation tests are effective stress and hydraulic gradient. Generally, the pores of soils become smaller under higher effective stress, and thus the hydraulic conductivity would be lower. The effective stress also has a similar effect on geotextiles. When subjected to higher effective stresses, the permeability of geotextiles decreases as a result of the reduction of pore size. In addition, the reduced pore sizes would allow less fine soil particles to pass through and migrate downstream.

On the other hand, higher hydraulic gradient would not only induce higher effective stress in the soil, but also the increased seepage force is more likely to carry fine particles downstream. However, the hydraulic conductivity of the filtration system may either be lower or higher depending on whether clogging/blinding or piping takes place or not. The combined effect can only be evaluated by the results of the tests on the geotextile/soil filtration system that simulates the actual flow condition.

\section{Gradient ratio test and hydraulic conductivity ratio test}

Among the test methods available for evaluating the performance of geotextile/ soil filtration systems, gradient ratio (GR) test and hydraulic conductivity ratio (HCR) test are the two most often used performance tests.

The two major advantages of the GR test (ASTM D5101-90) are its simplicity and its relatively longer history (Haliburton and Wood, 1982). Both the hydraulic conductivity and the value of gradient ratio can be determined from the test. For sandy soils, the specimen is prepared by water pluviation or wet tamping. However, as indicated by Fannin et al. (1994), the pluviation procedure can lead to segregation of the soil particles. Fischer et al. (1999) have studied the influence of procedural variables on the GR tests. The variables they looked into included purging with carbon dioxide, addition of algicide, method of soil placement, geotextile soaking, saturation rate, and so on. Among the changes of the ASTM standards they recommended, the most important ones were: requirement of longer testing period and system purging with carbon dioxide, use of algicide and microscreen, and apparatus modification to allow compaction of the soil specimen.

HCR test (ASTM D5567-94) is more difficult to conduct than GR test (Williams and Abouzakhm, 1989). The HCR test requires the use of flexible-wall permeameter and pressure/flow control system. However, the ASTM standards suggest that HCR test should be used to evaluate the performance of undisturbed or compacted soil specimens that have a hydraulic conductivity less than or equal to $5 \times 10^{-4} \mathrm{~m} / \mathrm{s}$. For more permeable soils, the filtration behavior should better be determined by the GR test. As a result, it seems that engineers must make the decision on which type of test to be used based upon the range of hydraulic conductivity. Since there were only very limited number of studies focused on comparing the results of these two tests, the differences between their results and the implication on engineering design are not fully understood. 
The objective of the described research was to investigate the hydraulic behavior of geotextile/soil filter under different flow conditions imposed by the HCR tests and the GR tests. The results of the two tests are compared in order to determine the effect of confining stress and hydraulic gradient on the geotextile/soil filter system.

\section{Material properties}

The experimental program consisted of performing GR tests and HCR tests on geotextile/soil systems consisted of 4 nonwoven geotextiles and 4 sandy soils.

The sandy soil tested was obtained from Tochien River in Hsinchu, Taiwan. The content of fine particles that pass through \#200 sieve was about 5\%. The soils used for testing were made up by sieving out the fines and re-mixing with the particles retained on \#200 sieve. The four sandy soil samples contained 5\%, 10\%, 20\%, and $30 \%$ of fines, respectively. The soils were classified as poorly graded sand (SP) and silty sand (SP-SM) according to the Unified Soil Classification System (USCS). The properties of the soils are listed in Table 1. The grain size distribution curves are shown in Fig. 1.

The geotextiles used as the filter fabrics in this study are all nonwoven geotextiles. NW-A is a heat-bonded nonwoven geotextile. NW-B, NW-C, and NW-D are needlepunched nonwoven geotextiles. Table 2 is a list of major properties of the geotextiles samples.

\section{Testing equipment and procedure}

\subsection{Gradient ratio test}

The GR apparatus used in this study is similar to the conventional GR test (Fig. 2). Following the suggestion made by Fannin et al. (1994), the GR test cells have energy dissipation plates to keep the influent water stream from hitting the soil

Table 1

Properties of soil tested

\begin{tabular}{lcccc}
\hline Soil & 1 & 2 & 3 & 4 \\
\hline Content of fines $(\%)$ & 5 & 10 & 20 & 30 \\
$d_{10}(\mathrm{~mm})$ & 0.11 & 0.05 & 0.021 & 0.018 \\
$d_{50}(\mathrm{~mm})$ & 0.2 & 0.195 & 0.185 & 0.180 \\
$d_{85}(\mathrm{~mm})$ & 0.55 & 0.53 & 0.51 & 0.48 \\
$C_{u}$ & 2.17 & 4.00 & 9.13 & 10.56 \\
$C_{c}$ & 1.13 & 2.78 & 6.10 & 1.69 \\
Soil classification $(\mathrm{USCS})$ & $\mathrm{SP}$ & $\mathrm{SP}-\mathrm{SM}$ & 1.761 & $\mathrm{SM}$ \\
Maximum dry density $\left(\mathrm{g} / \mathrm{cm}^{3}\right)$ & 1.653 & 1.694 & 13.6 & 1.830 \\
Optimum water content $(\%)$ & 17.8 & 14.3 & & 11.2 \\
\hline
\end{tabular}




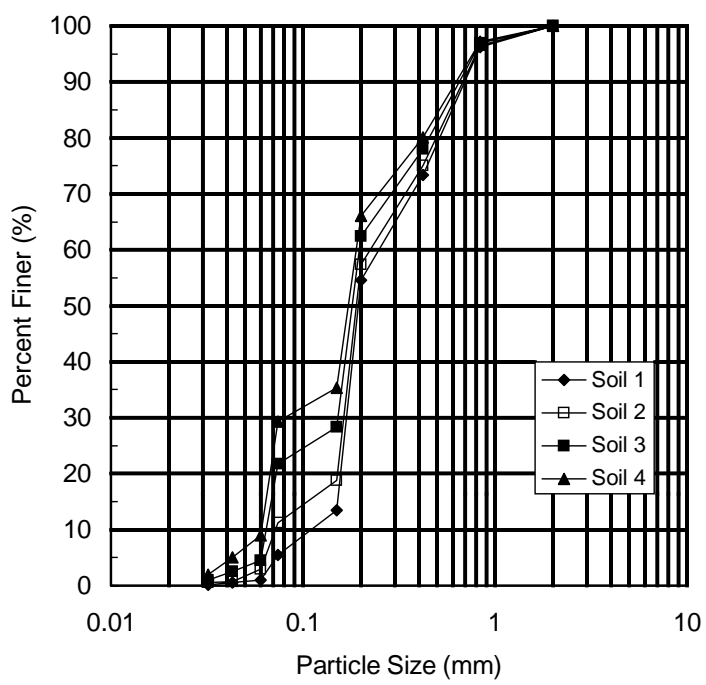

Fig. 1. Particle size distribution curves of soil tested.

Table 2

Properties of geotextiles tested ${ }^{\mathrm{a}}$

\begin{tabular}{lllllll}
\hline Properties & Unit & Test method & NW-A & NW-B & NW-C & NW-D \\
\hline Weight & $\mathrm{g} / \mathrm{m}^{2}$ & ASTM D3776 & 190 & 106 & 204 & 458 \\
Thickness & $\mathrm{mm}$ & ASTM D1777 & 0.56 & 1.524 & 2.864 & 4.318 \\
Permittivity & $1 / \mathrm{s}$ & ASTM D4491 & 1.1 & 2.61 & 2.27 & 1.34 \\
Hydraulic conductivity & $\mathrm{m} / \mathrm{s}$ & ASTM D4491 & $6.5 \times 10^{-4}$ & $4.0 \times 10^{-3}$ & $5.2 \times 10^{-3}$ & $5.8 \times 10^{-3}$ \\
Apparent opening size $\left(O_{95}\right)$ & $\mathrm{mm}$ & ASTM D4751 & 0.1 & 0.3 & 0.21 & 0.149 \\
\hline
\end{tabular}

${ }^{a}$ Note: Data obtained from Dupont (1994) and Trevira Spunbond Business Group (1993).

directly such that the scouring problem could be minimized. The soil specimens were prepared by compacting soils in the detachable steel mold. The soils were compacted with a water content $3 \%$ wetter than the optimum water content determined by the ASTM D698 standard Proctor compaction procedure. The geotextile specimen was placed on top of a metal mesh with an opening size of $1.0 \mathrm{~mm}$. The vertical position of the mesh can be adjusted to accommodate geotextile specimens of different thickness. Care was taken to make sure that the geotextile specimens were in perfect contact with the soil.

One of the drawbacks of the GR test is that the soil specimen could not be saturated with back pressure. Therefore, in order to enhance the saturation of the specimen, carbon dioxide gas was forced through the GR test cell and then deaired tap water was introduced into the cell from the bottom of the specimen to flush out trapped gas bubbles. 


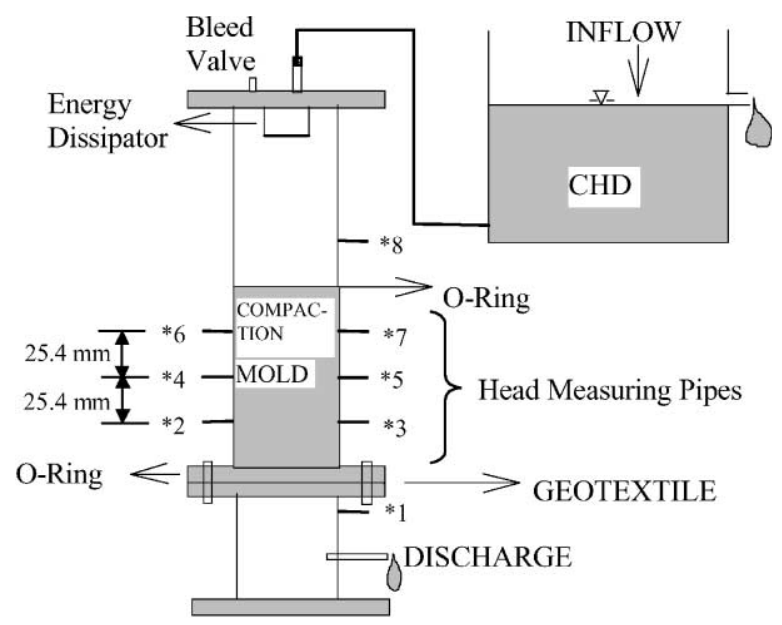

Fig. 2. Schematic system setup of gradient ratio test.

Water for permeation was supplied from the constant head device (CHD). Effluent water was collected with graduated cylinders. The tests started out by permeation of water with a hydraulic gradient of 1 . The permeation continued until the flow rate had been steady and the permeation period was no shorter than $48 \mathrm{~h}$. The hydraulic gradient was then raised to 5 , to continue the tests for at least another $48 \mathrm{~h}$.

The gradient ratios of the filtration systems were computed with the following equation:

$$
G R=\frac{i_{\mathrm{f}}}{i_{\mathrm{s}}}
$$

where $i_{\mathrm{f}}$ and $i_{\mathrm{s}}$ are the hydraulic gradient of the filter zone and the soil, respectively. These two values can be computed with the following equations:

$$
\begin{aligned}
& i_{\mathrm{f}}=\frac{\left(H_{2}+H_{3}\right) / 2-H_{1}}{25.4+T_{\mathrm{g}}}, \\
& i_{\mathrm{s}}=\frac{\left(H_{6}+H_{7}\right) / 2-\left(H_{2}+H_{3}\right) / 2}{50.8} .
\end{aligned}
$$

Thus

$$
G R=\frac{i_{\mathrm{f}}}{i_{\mathrm{s}}}=\frac{50.8}{\left(25.4+T_{\mathrm{g}}\right)} \times \frac{\left(H_{2}+H_{3}\right)-\left(2 \times H_{1}\right)}{\left(H_{6}+H_{7}\right)-\left(H_{2}+H_{3}\right)},
$$

where, $H_{n}$ is the reading in the head-measuring tubes $(\mathrm{mm}) ; T_{\mathrm{g}}$ is the thickness of geotextile $(\mathrm{mm})$.

\subsection{Hydraulic conductivity ratio test}

Flexible-wall permeameters were used to conduct the HCR tests. The soil specimens were prepared by compacting moist soil in a $101.6 \mathrm{~mm}$-diameter Proctor 
compaction split mold. The compacted soil specimens were then moved onto the pedestal of the permeameter. The geotextile was then put on top of the soil specimen. The rest of the setup procedure was similar to standard hydraulic conductivity test using flexible-wall permeameter (Fig. 3).

The sequence of increasing the effective stress and hydraulic gradient during each HCR test is listed in Table 3. The effective stress increased from 19.6 to $245 \mathrm{kPa}$ while

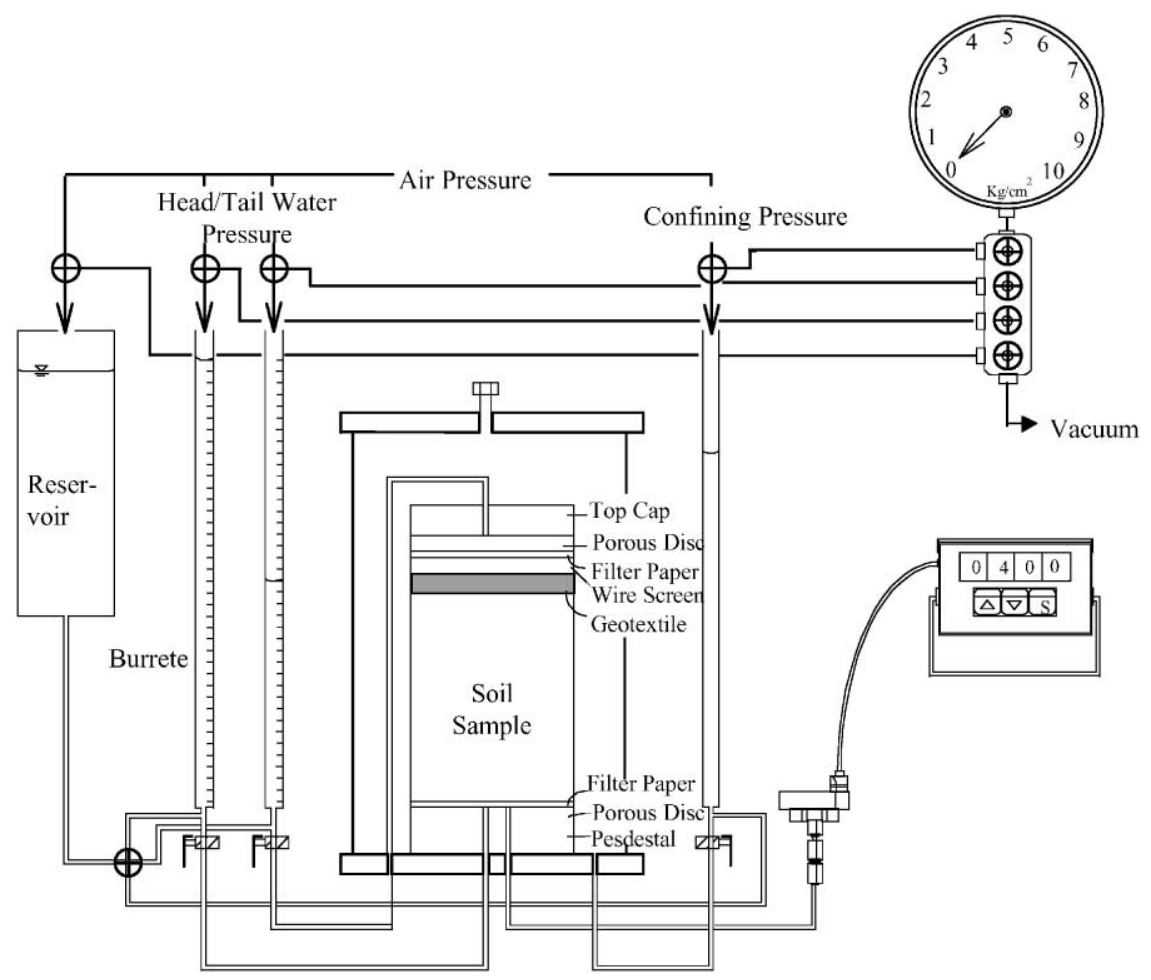

Fig. 3. Schematic diagram of system setup of hydraulic conductivity ratio test.

Table 3

Sequence of applying effective stress and hydraulic gradient in hydraulic gradient ratio test

\begin{tabular}{lllllr}
\hline Sequence & $\begin{array}{l}\text { Effective } \\
\text { stress } \sigma^{\prime}(\mathrm{kPa})\end{array}$ & $\begin{array}{l}\text { Hydraulic } \\
\text { gradient } i\end{array}$ & Sequence & $\begin{array}{l}\text { Effective } \\
\text { stress } \sigma^{\prime}(\mathrm{kPa})\end{array}$ & $\begin{array}{l}\text { Hydraulic } \\
\text { gradient } i\end{array}$ \\
\hline -KS & 19.6 & 1.0 & - KSG7 & 98.1 & 20.0 \\
- KSG1 & 19.6 & 1.0 & - KSG8 & 98.1 & 54.8 \\
- KSG2 & 19.6 & 4.0 & - KSG9 & 98.1 & 106 \\
- KSG3 & 34.3 & 4.0 & - KSG10 & 196 & 106 \\
-KSG4 & 34.3 & 10.0 & - KSG11 & 196 & 200 \\
-KSG5 & 68.7 & 10.0 & - KSG12 & 245 & 200 \\
-KSG6 & 68.7 & 20.0 & - KSG13 & 245 & 300 \\
\hline
\end{tabular}


the hydraulic gradient was raised from 1 to 300. During each increment of the hydraulic gradient, the average effective stress was maintained at a constant value. On the other hand, the hydraulic gradient was kept constant while the effective stress increased.

\section{Results and discussion}

\subsection{Gradient ratio tests}

The results of the GR tests are tabulated in Table 4. The hydraulic conductivity of all the systems tested became stable within $48 \mathrm{~h}$. This is in accordance with what Fischer et al. (1999) found in their study. The compacted soil allowed less internal movement of soil particles such that there was a lower potential for densification and a smaller reduction in permeability with time. As a result, the stabilization of flow was reached much earlier than conventional GR tests.

Judging from the test results, there appeared to be no serious clogging in the filtration zones since all the gradient ratio values were less than 3 . In most cases, the

Table 4

Results of gradient ratio tests

\begin{tabular}{|c|c|c|c|c|c|}
\hline \multirow[b]{2}{*}{ Soil } & \multicolumn{3}{|c|}{ Hydraulic gradient $i=1$} & \multicolumn{2}{|c|}{ Hydraulic gradient $i=5$} \\
\hline & 1 & 3 & 4 & 1 & 4 \\
\hline
\end{tabular}

(a) $\mathrm{NW}$-A-heat bonded nonwoven geotextile

$\begin{array}{lllllllll}k_{\text {system }}(\mathrm{m} / \mathrm{s}) & 1.3 \times 10^{-5} & 1.2 \times 10^{-6} & 7.7 \times 10^{-7} & 8.3 \times 10^{-7} & 2.6 \times 10^{-6} & 9.4 \times 10^{-7} & 6.9 \times 10^{-7} & 4.9 \times 10^{-7} \\ k_{\text {soil }}(\mathrm{m} / \mathrm{s}) & 1.5 \times 10^{-5} & 1.8 \times 10^{-6} & 7.3 \times 10^{-7} & 6.7 \times 10^{-7} & 3.3 \times 10^{-6} & 9.6 \times 10^{-7} & 4.8 \times 10^{-7} & 5.3 \times 10^{-7} \\ k_{\text {filter }}(\mathrm{m} / \mathrm{s}) & 9.6 \times 10^{-6} & 1.1 \times 10^{-6} & 8.4 \times 10^{-7} & 3.3 \times 10^{-6} & 2.0 \times 10^{-6} & 5.9 \times 10^{-7} & 1.2 \times 10^{-6} & 2.0 \times 10^{-6} \\ \mathrm{GR} & 1.5 & 1.7 & 0.86 & 0.21 & 1.7 & 1.6 & 0.39 & 0.27\end{array}$

(b) $N W$-B-needle punched nonwoven geotextile

$k_{\text {system }}(\mathrm{m} / \mathrm{s}) \quad 3.0 \times 10^{-5} \quad 3.2 \times 10^{-6} \quad 1.3 \times 10^{-6} \quad 1.7 \times 10^{-7} \quad 1.4 \times 10^{-5} \quad 1.2 \times 10^{-6} 1.8 \times 10^{-7} 1.7 \times 10^{-7}$

$k_{\text {soil }}(\mathrm{m} / \mathrm{s}) \quad 2.3 \times 10^{-5} \quad 3.1 \times 10^{-6} \quad 8.4 \times 10^{-7} \quad 1.0 \times 10^{-7} \quad 1.0 \times 10^{-5} 9.5 \times 10^{-7} 1.2 \times 10^{-7} \quad 9.6 \times 10^{-8}$

$k_{\text {filter }}(\mathrm{m} / \mathrm{s}) \quad 5.2 \times 10^{-5} \quad 6.9 \times 10^{-6} \quad 1.4 \times 10^{-6} \quad 3.3 \times 10^{-7} 1.5 \times 10^{-5} 2.5 \times 10^{-6} 2.0 \times 10^{-7} \quad 5.7 \times 10^{-7}$

$\begin{array}{lllllllll}\text { GR } & 0.45 & 0.45 & 0.60 & 0.31 & 0.7 & 0.38 & 0.59 & 0.17\end{array}$

(c) NW-C-needle punched nonwoven geotextile

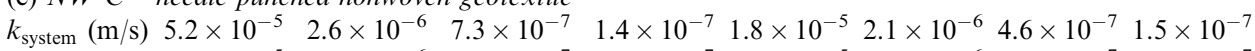

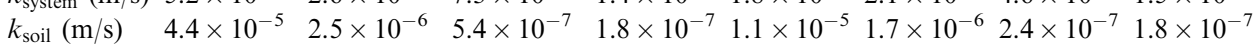

$k_{\text {filter }}(\mathrm{m} / \mathrm{s}) \quad 7.0 \times 10^{-5} \quad 1.2 \times 10^{-5} \quad 7.5 \times 10^{-7} \quad 6.9 \times 10^{-8} \quad 3.8 \times 10^{-5} \quad 3.5 \times 10^{-6} 1.7 \times 10^{-6} \quad 7.3 \times 10^{-8}$

$\begin{array}{lllllllll}\text { GR } & 0.63 & 0.20 & 0.72 & 2.6 & 0.28 & 0.50 & 0.15 & 2.4\end{array}$

(d) NW-D-needle punched nonwoven geotextile

\begin{tabular}{lllllllll}
$k_{\text {system }}(\mathrm{m} / \mathrm{s})$ & $2.1 \times 10^{-5}$ & $2.9 \times 10^{-6}$ & $5.1 \times 10^{-7}$ & $3.0 \times 10^{-7}$ & $1.1 \times 10^{-5}$ & $2.0 \times 10^{-6}$ & $4.0 \times 10^{-7}$ & $8.7 \times 10^{-8}$ \\
$k_{\text {soil }}(\mathrm{m} / \mathrm{s})$ & $2.3 \times 10^{-5}$ & $1.8 \times 10^{-6}$ & $5.0 \times 10^{-7}$ & $1.8 \times 10^{-7}$ & $9.1 \times 10^{-6}$ & $1.8 \times 10^{-6}$ & $5.1 \times 10^{-7}$ & $5.7 \times 10^{-8}$ \\
$k_{\text {filter }}(\mathrm{m} / \mathrm{s})$ & $1.9 \times 10^{-5}$ & $7.0 \times 10^{-6}$ & $4.7 \times 10^{-7}$ & $1.3 \times 10^{-6}$ & $1.1 \times 10^{-5}$ & $2.8 \times 10^{-6}$ & $2.9 \times 10^{-7}$ & $3.2 \times 10^{-7}$ \\
$\mathrm{GR}$ & 1.2 & 0.25 & 1.1 & 0.14 & 0.81 & 0.64 & 1.8 & 0.18 \\
\hline
\end{tabular}


gradient ratios were less than 1 . In other words, for most of the filtration systems tested, the hydraulic conductivity of the filter zone was greater than that of the soil. This suggests that there might be some fine soil particles flushed out from the filter zone during the tests. Nevertheless, the flow rates measured from most of the gradient ratio tests stabilized in less than $2 \mathrm{~h}$. The effluent water remained clear throughout the test period. As a result, there did not appear to be any piping or significant loss of soil.

The hydraulic conductivity of the geotextile/soil filtration system decreased with the content of fines of the soils (Table 4). In addition, the properties of various geotextiles did not seem to have a significant effect on the hydraulic conductivity.

The ratios of the values of hydraulic conductivity measured under two different hydraulic gradients are shown in Fig. 4. The variation of the hydraulic conductivity with the hydraulic gradient is evident. In almost all cases, the hydraulic conductivity of the soil and the overall system decreased when the hydraulic gradient was increased. The most possible reason for the decrease of hydraulic conductivity is that the higher hydraulic gradient induced higher seepage force in the soil and the fine particles were carried downstream under higher hydraulic gradient and remained in the pores near the effluent end.

However, in a few cases, the variation of the hydraulic conductivity of the filter zone showed an opposite trend (Table 4). In these cases, the hydraulic conductivity of the filter zone increased when subjected to higher hydraulic gradient. The geotextile/soil combinations of these cases were NW-A/Soil 3, NW-B/Soil 4, and $\mathrm{NW}-\mathrm{C} /$ Soil 3. This increase might have resulted from the loss of finer soil particles in the filter zone, which is, in turn, related to the internal stability of the soil.

Bhatia et al. (1995) looked into the effect of internal stability of the soil structure on the filtration systems. They defined that the soil structure is internally unstable when the coefficient of gradation of the soil is larger than $7\left(c_{c}>7\right)$. They found that for soils with $c_{c}<4$, the properties of the geotextiles have almost no influence on the filtration performance. On the other hand, Lafleur (1999) has conducted filtration tests on "problematic" soils with $c_{u}>8$. The results showed that the intensity of the

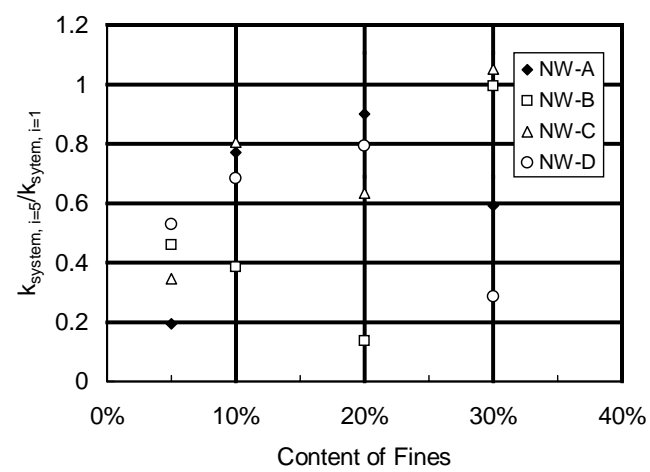

Fig. 4. Ratios of hydraulic conductivity values under $i=5$ and 1 . 
hydraulic gradients and time allowed for the mechanisms of either piping, bridging or blinding, to have developed fully. However, for internally unstable soils, piping failure can occur if the geotextiles with large opening sizes and high porosity were used. In this study, the AOS of the geotextiles were not large enough for serious piping to develop as judged by the criteria suggested by Lafleur (1999). Although the $c_{c}$ of Soil 3 is 6.1 and the $c_{u}$ of Soil 3 and Soil 4 are larger than 8, there was no visible evidence of significant soil loss. Nevertheless, the internal stability problems described by Bhatia et al. (1995) and Lafleur (1999) may still be the most possible reason for the increase of hydraulic conductivity.

Another important finding from the results of the GR tests is that the increase of hydraulic gradient did not have a significant effect on the gradient ratio values of the geotextile/soil systems tested (Table 4). The only exceptions were the systems consisted of NW-C/Soil 2 and NW-D/Soil 2 where the gradient ratios became 2.5 times of the original values. For these two cases, the hydraulic conductivity of the filter zone and the soil both decreased. However, the hydraulic conductivity of the filter zone decreased more than that of the soil. There could be an occurrence of some blinding due to the movement of fine particles to the filter zone. For all other tests, the increase of the overall hydraulic gradient has a more significant effect on the soil than on the filter zone. Thus, the GR did not increase.

\subsection{Hydraulic conductivity ratio tests}

The results of HCR tests are presented and discussed in this section. In general, the hydraulic conductivity decreased gradually as the tests proceeded. Both the increase of average effective stress and hydraulic gradient led to the decrease (Figs. 5 and 6).

Considering the materials tested, it seems that the content of fines of the soils controlled the hydraulic conductivity of the filtration systems. On the contrary, the geotextiles did not appear to have a significant influence on the results. Furthermore, it has to be noted that there were three cases which the hydraulic conductivity of the systems experienced a sudden drop and then was followed by a sharp rise. Following the unexpected deviation, when the effective stress and hydraulic conductivity were raised, the behavior of the systems seemed to conform to the expected trend again. These three particular filtration systems were made up of combinations of NW-B/ Soil 2, NW-B/Soil 3, and NW-D/Soil 2. The possible reasons for this phenomenon will be explained later in this section.

Fig. 7 shows that the hydraulic conductivity decreased with the increase of effective stress. The reduction was due to the reduction of the pore size of the soil and the geotextile under higher effective stress. The variation of hydraulic conductivity of the filtration systems with hydraulic gradient is shown in Fig. 6. In most cases, the increase of effective stress at the downstream side of the specimens induced by higher hydraulic gradient contributed to a decrease in the hydraulic conductivity. The effect should not be significant for the range of hydraulic gradient used in routine laboratory tests. However, for internally unstable soils, high hydraulic gradients may cause either clogging in the pores or piping. 

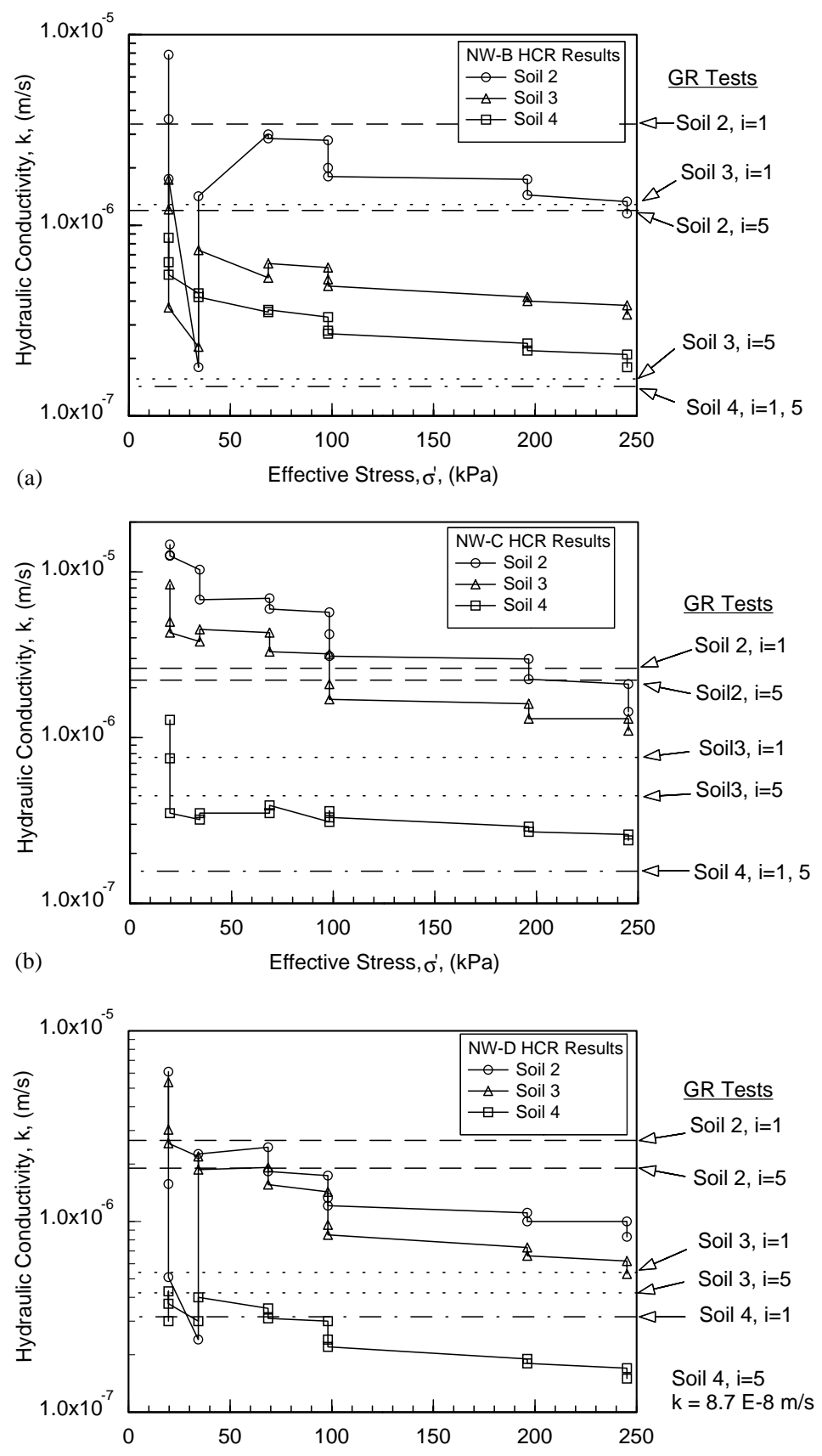

(c)

Effective Stress, $\sigma^{\prime}(\mathrm{kPa})$

Fig. 5. Variation of the hydraulic conductivity with average effective stress: (a) NW-B; (b) NW-C; (c) NW-D. 


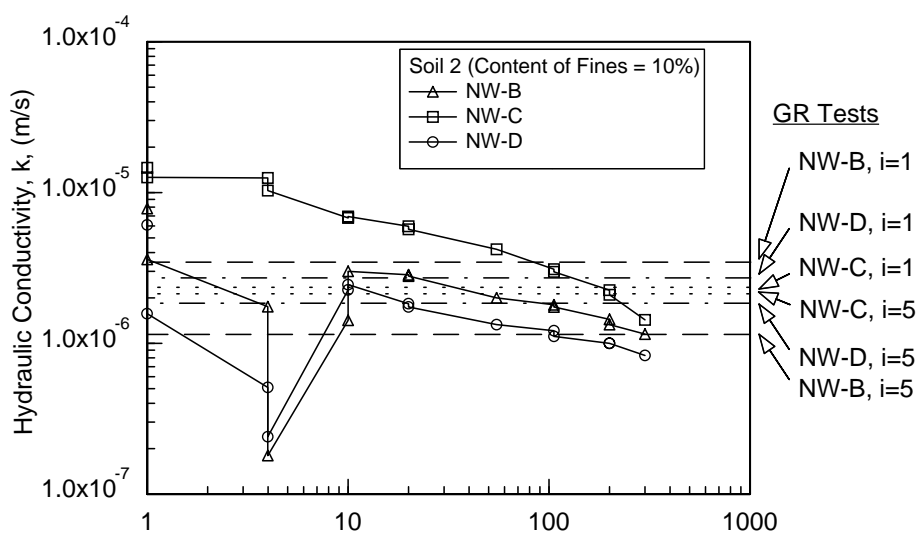

(a)

Hydraulic Gradient, i

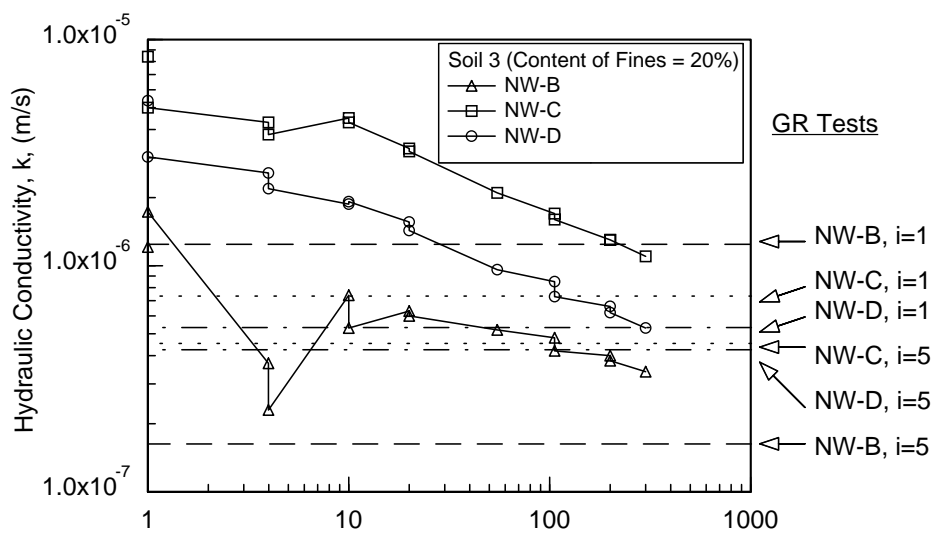

(b)

Hydraulic Gradient, i

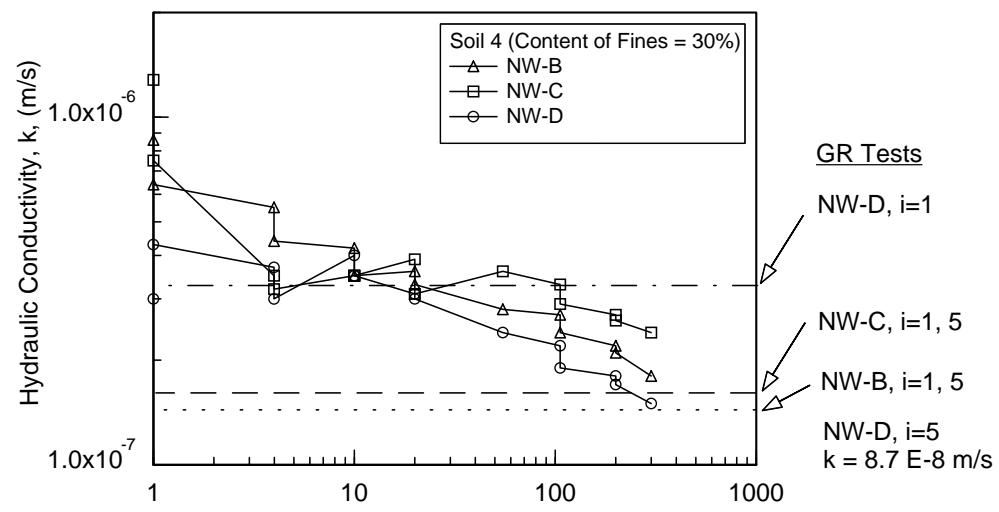

(c)

Hydraulic Gradient, i

Fig. 6. Variation of the hydraulic conductivity with hydraulic gradient: (a) Soil 2; (b) Soil 3; (c) Soil 4. 


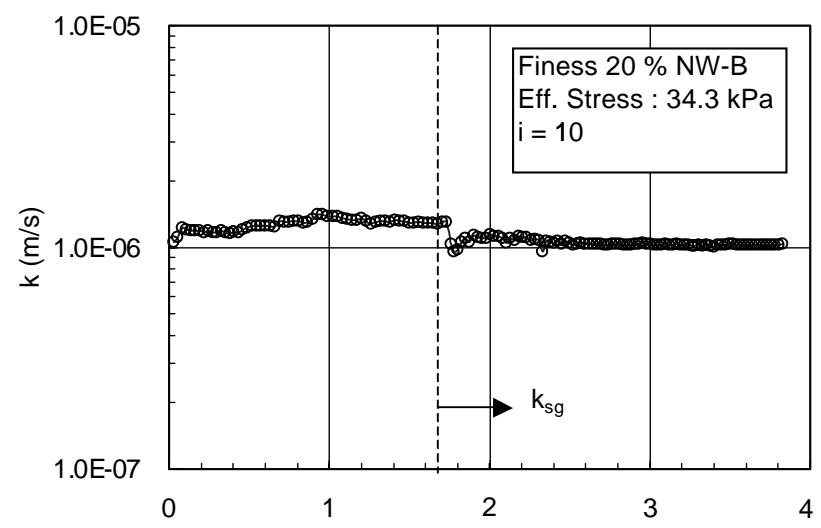

(a)

Pore Volume

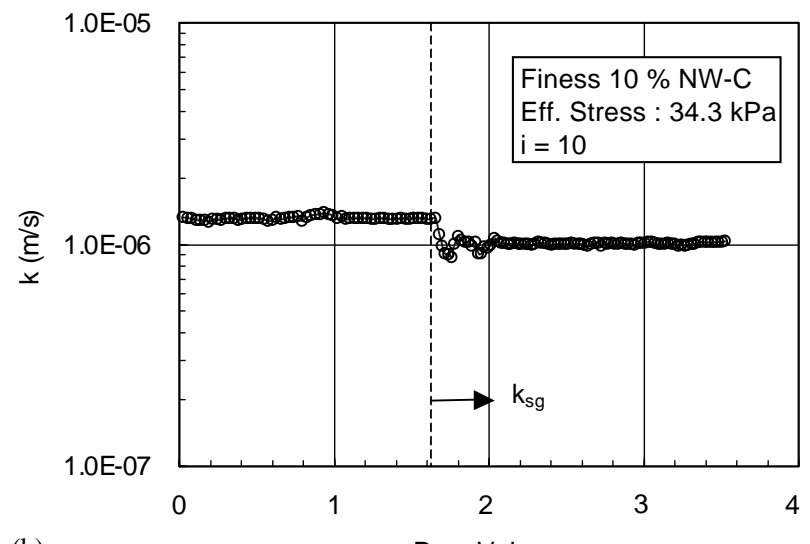

(b)

Pore Volume

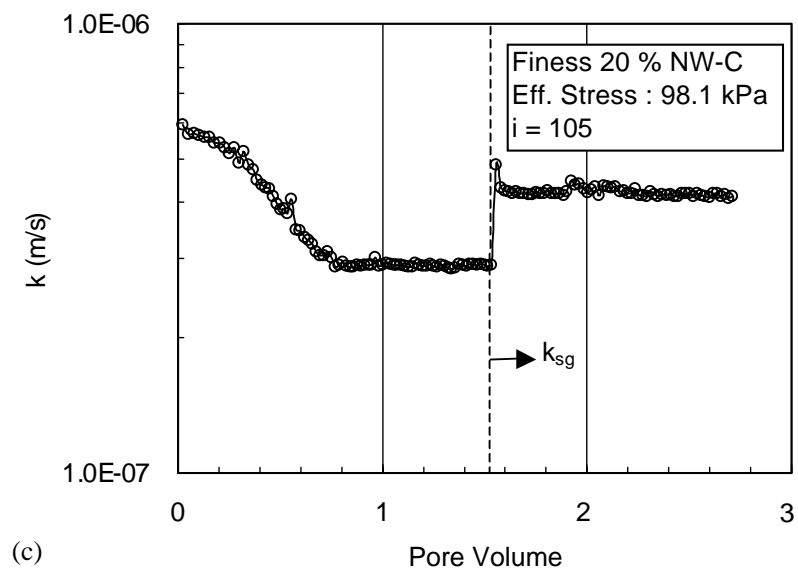

Fig. 7. Results of HCR tests on three geotextile/soil filtration systems: (a) NW-B/Soil 3; (b) NW-C/Soil 2; (c) NW-C/Soil 3. 
By comparing the test results shown in Figs. 5 and 6, it seems that for the range of effective stress and hydraulic gradient generally used in laboratory tests, the effect of increasing hydraulic gradient on the hydraulic conductivity is more pronounced than the effect of increasing effective stress. Similar to what the GR test results indicate, the soil seemed to play a much more important role regarding the hydraulic conductivity of the system in HCR tests. The main reason is that in these tests, the soils are much thicker and have significantly lower hydraulic conductivity than the geotextiles. The soil basically dominates the hydraulic behavior of the filtration system. Unless clogging or piping occurs, the hydraulic conductivity of the geotextile/soil filtration system is controlled by the soil, especially when the systems are tested under large effective stress and high hydraulic gradient.

The geotextile/soil filtration systems whose hydraulic conductivity of the filter zone increased when the hydraulic gradient was increased in GR tests also behaved differently in HCR tests. First, the final hydraulic conductivity of the NW-C/Soil 3 system was higher than those of the other two systems with Soil 3 (Fig. 6(b)). This could have been caused by the higher hydraulic conductivity in the filter zone of the NW-C/Soil 3 system. On the other hand, the NW-B/Soil 3 (Fig. 6(b)) and NW-C/ Soil 4 (Fig. 6(c)) systems demonstrated the increase of hydraulic conductivity with the increase of hydraulic gradient from $i=4$ up to 55, which was a deviation from the overall decreasing trend of hydraulic conductivity with increasing hydraulic gradient. Apparently, both GR test and HCR test were able to show this peculiar behavior of the filtration systems.

\subsection{Influence of effective stress and hydraulic gradient in HCR tests}

The deviations of the three test results from the slowly decreasing hydraulic conductivity (Figs. 5 and 6) required further investigations. These three filtration systems are NW-B/Soil 2, NW-B/Soil 3, and NW-D/Soil 2. The sudden and substantial drop in hydraulic conductivity occurred under relatively low effective stress and hydraulic gradient. It seems that the deviation was most likely to occur for Soil 2 with $10 \%$ of fines. As the content of fines increase, the tendency to deviate from the smooth path became less obvious. The filtration systems consist of Soil 4 in which $30 \%$ of fines were the most stable ones. However, for the NW-C/Soil 4 system, a slight decrease and then increase of hydraulic conductivity in the early stage of the test could still be observed.

In order to investigate whether experimental errors led to the deviation, additional tests were performed. These three additional tests are NW-B/Soil 3, NW-C/Soil 2, and NW-C/Soil 3. Among them, the NW-B/Soil 2 system is the suspected "unstable" system indicated by previous tests. These tests were performed following the conventional HCR test procedure and the results are shown in Fig. 7. These results are also tabulated in Table 5. There were no sharp changes in the hydraulic conductivity of the systems throughout these tests. However, for the NW-C/Soil 3 system, the hydraulic conductivity of the soil, $k_{\mathrm{s}}$, slowly decreased from the beginning of the permeation and then stabilized after approximately 0.8 pore volume of water flowed through. The initial decrease of $k_{\mathrm{s}}$ should have resulted from 
Table 5

Results of three hydraulic conductivity ratio tests

\begin{tabular}{|c|c|c|c|c|c|c|c|c|c|}
\hline \multicolumn{2}{|c|}{ Filtration system } & \multicolumn{2}{|c|}{ Boundary condition } & \multirow{2}{*}{$\begin{array}{l}\text { Sequential tests } \\
k_{\mathrm{sg}}(\mathrm{m} / \mathrm{s})\end{array}$} & \multicolumn{3}{|c|}{ Results of additional HCR tests } & \multicolumn{2}{|l|}{ Results of GR test } \\
\hline Soil & Geotextile & $\begin{array}{l}\text { Effective stress, } \\
\sigma^{\prime}(\mathrm{kPa})\end{array}$ & $\begin{array}{l}\text { Hydraulic } \\
\text { gradient, } i\end{array}$ & & $k_{\mathrm{s}}(\mathrm{m} / \mathrm{s})$ & $k_{\mathrm{sg}}(\mathrm{m} / \mathrm{s})$ & HCR & $k_{\text {system }}(\mathrm{m} / \mathrm{s}) i=1$ & $k_{\text {system }}(\mathrm{m} / \mathrm{s}) i=5$ \\
\hline 2 & NW-C & 34.3 & 10 & $6.8 \times 10^{-6}$ & $1.3 \times 10^{-6}$ & $1.0 \times 10^{-6}$ & 0.76 & $2.6 \times 10^{-6}$ & $2.1 \times 10^{-6}$ \\
\hline 3 & NW-B & 34.3 & 10 & $7.4 \times 10^{-7}$ & $1.3 \times 10^{-6}$ & $1.0 \times 10^{-6}$ & 0.76 & $1.3 \times 10^{-6}$ & $1.8 \times 10^{-7}$ \\
\hline 3 & NW-C & 98.1 & 106 & $1.7 \times 10^{-6}$ & $2.9 \times 10^{-7}$ & $4.1 \times 10^{-7}$ & 1.41 & $7.3 \times 10^{-7}$ & $4.6 \times 10^{-7}$ \\
\hline
\end{tabular}


consolidation of the soil by the induced seepage force. The hydraulic gradient of this test was 106 and was higher than those of the other two tests.

For the NW-B/Soil 3 combination, the hydraulic conductivity of the filtration system, $k_{\mathrm{sg}}$, were greater than those values determined under the same effective stress and hydraulic gradient of the systems in the tests shown in Figs. 5 and 6. For the other two tests on NW-C/Soil 2 and NW-C/Soil 3 systems, the hydraulic conductivity were lower than those determined by previous tests under the same effective stress and hydraulic gradient. However, the hydraulic conductivity of these two tests are very close to those determined by GR tests with $i=5$.

In addition, particle size analyses were performed on these soil specimens after the tests. For the NW-B/Soil 3 system, the results show that the proportion of fine particles in the soil near the geotextile, which was placed on top of the soil, increased (Fig. 8(a)). It is an evidence of the migration of fine particles towards the filter zone. Therefore, for this system, $k_{\mathrm{sg}}$ became lower than $k_{\mathrm{s}}$. The low combination of low effective stress and low hydraulic gradient also caused the movement of particles larger than No. 200 sieve and AOS. The larger particles also migrated towards the bottom of the specimen at the beginning of the test, but then got trapped in the middle of the specimen when the direction of water flow reversed. It is indicated in Fig. 8(a) that the middle and the top of the specimen had the highest and lowest percentage of the larger particles, respectively.

For the NW-C/Soil 2 system, there were only very little fine particles left near both ends of the specimen (Fig. 8(b)). However, the middle part of the soil had more fine particles than when the test began. It seems that the fine particles near both ends were carried by the water towards the middle part of the specimen and then got trapped in the pores. This also caused $k_{\mathrm{sg}}$ to be lower than $k_{\mathrm{s}}$. However, the particles larger than AOS migrated towards the bottom of the specimen remains there after the direction of the flow was reversed as shown in Fig. 8(b) indicating that the bottom had the highest percentage of the larger particles. When compared to Fig. 8(a), it seems that the higher percentage of the larger particles made them less easily to migrate. Similarly, the fine particles near both ends of the NW-C/Soil 3 system have also migrated towards the middle of the soil specimen (Figs. 8(c)). The increase of fine particles in specific zones caused a shift of the particle distribution curves such that the percentage of larger particles also varied. This migration first resulted in the initial decrease of $k_{\mathrm{s}}$. When the direction of water flow was reversed, some of the fine particles at the downstream side might have been flushed through the geotextile causing $k_{\mathrm{sg}}$ to become greater than $k_{\mathrm{s}}$. However, the middle part of the soil specimen still had more fine particles than both ends. It could also be noticed from Fig. 8(c) that the middle of the specimen had the least percentage of particles larger than AOS. It could be that these particles migrated towards the bottom of the specimen. When the direction of flow reversed, these particles had a tendency to move in the direction of the flow. Under the combination of the effective stress and in particular high hydraulic gradient, the larger particles in the middle layer were carried toward the top of the specimen. However, the larger particles at the bottom were not as easy to move because the interlocking effect due to the higher percentage of the larger particles. 

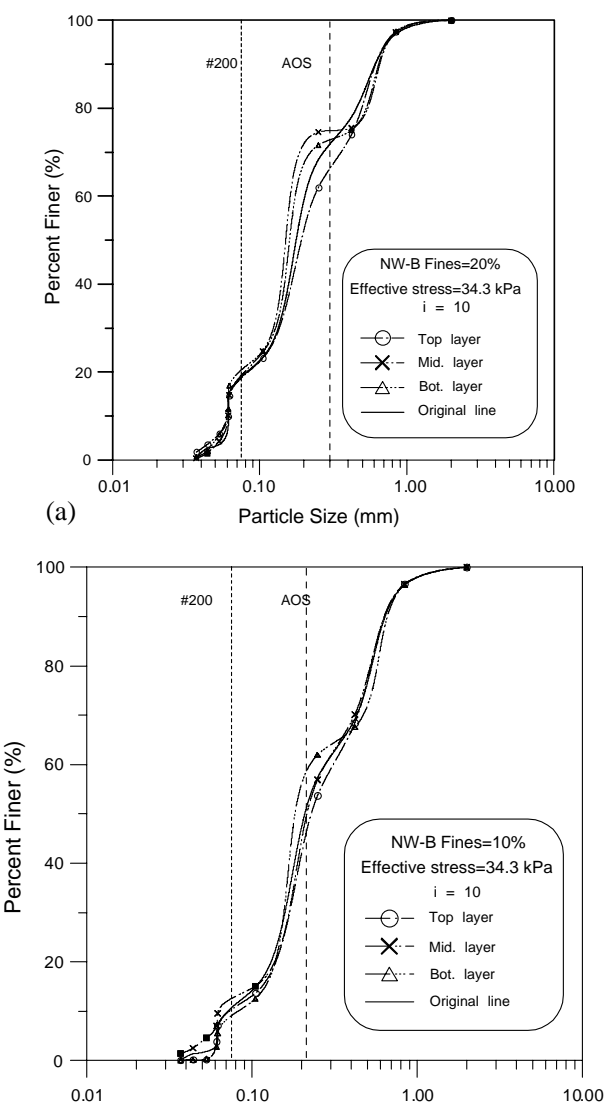

(b)

Particle Size $(\mathrm{mm})$

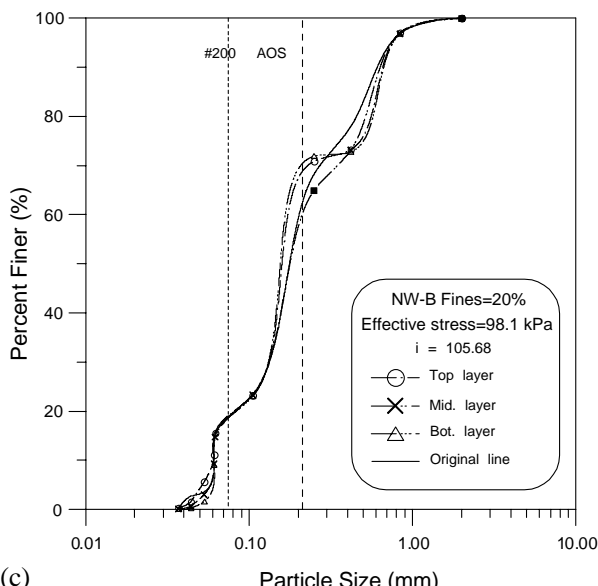

Fig. 8. Particle size distribution after the HCR tests: (a) NW-B/Soil 3; (b) NW-C/Soil 2; (c) NW-C/Soil 3. 
Based on the above analysis, it can be concluded that the reason for the differences between the results of sequential tests and ordinary HCR tests is the procedure of applying the effective stress and hydraulic gradient. When the effective stress and the hydraulic gradient were increased incrementally, the soil particles were loosely packed under lower effective stress and moved downstream with water under the action of seepage force. The fine particles might accumulate near the filter zone caused the blinding/clogging of the system or they might accumulate near the middle of the soil specimens and cause the reduction of $k_{\mathrm{s}}$ and $k_{\mathrm{sg}}$. On the contrary, if the test had started out by applying a large enough effective stress such that all the soil particles are well confined and not allowed to migrate, blinding/clogging of the system would not occur under the same or even larger seepage force.

Accordingly, it is suggested that the HCR test should be treated strictly as a performance test. The test should be conducted under the effective stress and, if possible, the hydraulic gradient that the filtration will be subjected to in the field. In addition, this effective stress should be fully applied to the specimen before the permeation begins. For the filtration systems like the three particular ones in this study, testing with effective stress higher than the field condition will not be able to give meaningful results. On the other hand, the hydraulic gradient applied should be low enough to simulate the field condition. Using a high hydraulic gradient may speed up the test but could give erroneous results. Fine particles brought to the filter zone under the seepage force may cause blinding or clogging of the filtration system. However, the large seepage force induced by a much higher hydraulic gradient may flush away these fine particles such that no reduction of hydraulic conductivity will be detected.

\subsection{Comparison of results of $G R$ and HCR tests}

The hydraulic conductivity values of GR tests with hydraulic gradients of 1 and 5 are indicated in Figs. 5 and 6 along with the results of HCR tests for comparison. Generally, in hydraulic conductivity tests, the most important factor that controls the hydraulic conductivity is the void ratio of the soils. For hydraulic conductivity tests using flexible-wall permeameters, such as the ones used for HCR tests, the void ratio of the soil is reduced when the applied effective stress increases. On the other hand, for hydraulic conductivity tests using the fixed-wall permeameters, such as the GR test apparatus, as well as the flexible-wall permeameters, the result depends upon factors such as hydraulic gradient, degree of saturation, and so on. Generally, the range of variation of hydraulic conductivity of a specific soil should be wider for flexible-wall permeameters.

However, the results of the GR tests and HCR tests did not agree with the above statements. The hydraulic conductivity for GR tests with $i=1$ was close to the values determined from HCR tests at low effective stress. However, in most cases, the hydraulic conductivity measured with GR tests with $i=5$ were several times lower than the results of HCR tests. This seems to be contradictory to the fact that specimens of GR tests were not subjected to the applied effective stress and should have larger hydraulic conductivity. 
There are several possible reasons for the relationship between the results of these two types of tests. First, in GR tests, the specimens were not saturated with backpressure such that even the specimens were purged with $\mathrm{CO}_{2}$ to enhance saturation even if there was still air in specimens and reduced flow rate. Second, in the first stage of HCR tests, water flows through the geotextile and then the soil. There might be some loss of fine soil particles, which caused the hydraulic conductivity of the soil to increase. However, the condition should not be significant since the porous disk would also help to deter the migration of fine particles. Third, the fine soil particles near the filter zone were easier to migrate downstream in the GR tests since the effective stress was lower than that in HCR tests. These fine particles could cause decrease of the hydraulic conductivity of the filter zone or soil itself. Fourth, the large hydraulic gradient in HCR tests minimized the possibility of blinding. The large seepage force would have carried away the fine soil particles that may have caused blinding. This postulation can be supported by the response of hydraulic conductivity to the hydraulic gradient in the HCR tests that experience a sudden decrease and then increase of hydraulic conductivity under low effective stress and hydraulic gradient.

It should also be mentioned that since the nonwoven geotextiles used in this study had rather large opening sizes (approximately $d_{30}$ of the soils) there should be some loss of finer particles during the GR tests. However, the fact that the soil specimens were prepared by the standard compaction procedures might help the soil specimens to have a more stable structure and did not experience observable soil loss.

It can be concluded from these results that the soil governed the hydraulic conductivity of the geotextile/soil system. Nevertheless, for such systems with any specific soil, the geotextile did play an important role in affecting the hydraulic conductivity, especially at low effective stress. Systems with geotextiles of larger $O_{95}$ or higher permittivity had higher hydraulic conductivity. For example, for Soil 2, which has $10 \%$ fines, the hydraulic conductivity $k_{\mathrm{sg}}$ of the system with geotextile NW-B was the highest whereas the system with NW-D had the lowest.

\section{Conclusions}

The effect of boundary conditions of the geotextile/soil filtration system was investigated in this study. A series of GR tests and HCR tests were performed on filtration systems consisting of the combinations of 4 geotextiles and 4 sandy soils.

In general, the soil governs the hydraulic conductivity of the geotextile/soil system. However, for a specific soil, the geotextile with larger $O_{95}$ or higher hydraulic conductivity resulted in higher hydraulic conductivity of the filter system. The trend can be observed from the results of GR tests as well as HCR tests.

Although the HCR test may be the most appropriate test method for predicting the performance of the geotextile/soil filter system, the applied boundary condition is critical to the results and should be decided with great care before testing. The study showed that there was significant fluctuation of the hydraulic conductivity due to the variation of effective stress and hydraulic gradient. Therefore, not only the 
magnitude but also the sequence of applying the effective stress and hydraulic gradient should follow the expected field condition.

On the other hand, the control over the effective stress and the hydraulic gradient in conventional GR test is indeed quite limited. However, this study showed that the results of HCR tests might not necessarily be more reliable than the results of the GR tests. It is suggested that the less complicated GR test is as good as the HCR test for evaluating the clogging potential of the filter systems and determining their hydraulic conductivity for practical purposes.

\section{References}

Bhatia, S.K., Huang, Q., Hawkins, W.M., 1995. The soil-geotextile interface stability under sudden change in hydraulic condition. Proceedings of the Geosynthetics '95, Nashville, TN, USA, pp. 297315.

Dupont, 1994. Specification of the Nonwoven Geotextile Products.

Fannin, R.J., Vaid, Y.P., Shi, Y., 1994. A critical review of the gradient ratio test. Geotechnical Testing Journal, ASTM, GTJODJ 17 (1), 35-42.

Fischer, G.R., Mare, A.D., Holtz, R.D., 1999. Influence of procedural variables on the gradient ratio test. Geotechnical Testing Journal, ASTM, GTJODJ 22 (3), 22-31.

Haliburton, T.A., Wood, P.D., 1982. Evaluation of the US Army Corps of Engineer gradient ratio test for geotextile performance. Proceedings of the Second International Conference on Geotextiles, Vol. 1, pp. 97-101.

Lafleur, J., 1999. Selection of geotextiles to filter broadly graded cohesionless soils. Geotextiles and Geomembranes 17, 299-312.

Trevira Spunbond Business Group, 1993. Specification of the Nonwoven Geotextile Products.

Williams, N.D., Abouzakhm, M.A., 1989. Evaluation of geotextile-soil filtration characteristics using the hydraulic conductivity. Geotextiles and Geomembranes 8, 1-26. 